\title{
The changing politics of miscegenation
}

\author{
Mitchell Rolls
}

In an opinion piece in Hobart's Saturday Mercury Henry Reynolds, the noted historian of Aboriginal-settler Australian relations, raised the contentious issue of identity in respect to Tasmanian Aboriginal people of mixed heritage. ${ }^{1}$ In reclaiming and asserting a defiant Aboriginality, many Tasmanian Aborigines (and mainlanders too) obfuscate and/or ignore the fact that they are of mixed descent. Their identity, both cultural and personal, is subsumed into a proclaimed Aboriginality. Reynold's proposal that such people (in Tasmania anyway) might better be described as Creole drew the expected voices of dissent. For many of those proclaiming Aboriginality, Aboriginality constitutes both the sum and total of who they are and any scrutiny of this assumed identity invariably raises hackles. And there is good reason for this. Descendants of miscegenation, often conceived through violence, were for long the subjects of ostracism, concern and administrative contumely. At various points they were described as inheriting the worst characteristics of both races, as being irretrievably trapped in the chasm betwixt two cultures, as having no culture at all, and always as a problem. In some jurisdictions this led to ever finer and sillier gradations between such descendants so as to more securely locate them within the colonial order, thereby effecting greater administrative control. Descendants of mixed heritage were not granted the liberty to exist in their own complex right. They were instead conceived of as a group to whom things needed to be done in order to provide them with culture and an identity, or alternatively, to rid Australia of their presence. Sterilisation was one of many proposals put forward to effect the latter ${ }^{2}$ and assimilation became enacted policy. Little wonder then that many of Australia's indigenous people baulk at the notion of a hybrid identity. While such an identity would have the capacity to 'evad[e] the replication of ... binary categories' and allow for the 'develop[ment of] new anti-monolithic models of cultural exchange and growth', ${ }^{3}$ it is more widely regarded as a further and calculated denial of the authenticity of one's history, subjectivity and culture. ${ }^{4}$

Whilst many remain empathetic to and understand the need of those of mixed descent to 're-present themselves as coherent people with a sustainable historicized subjectivity', 5 the elision of one (or more) cultural and biological heritages in

Cited in Pos 2002: 37-8.

See Kidd 1997: 137-8.

Ashcroft et al. 1995: 183.

See Anderson 1997. 
proclamations of identity is a phenomenon deserving of analysis, not uncritical nor tacit endorsement offered under the presumption of salutary support. Furthermore, when considered within the context of today's orthodox rhetoric describing black/white relations, the politically efficacious and sometimes faddish elision of heritages raises some unsettling possibilities.

$$
* * * *
$$

The assimilation era and its authorising policies have understandably become the subject of scrutiny and criticism. The Initial Conference of Commonwealth and State Aboriginal Authorities held in Canberra in April 1937 determined

That this Conference believes that the destiny of the natives of aboriginal origin, but not of the full blood, lies in their ultimate absorption by the people of the Commonwealth, and it therefore recommends that all efforts be directed to that end. ${ }^{6}$

AO Neville, Western Australian Commissioner of Native Affairs, was an influential delegate. In asking 'Are we going to have a population of 1,000,000 blacks in the Commonwealth, or are we going to merge them into our white community and eventually forget that there ever were any aborigines in Australia,' Neville confirmed that the conference took the notion of absorption literally. In the vernacular of that era, the plan for Aboriginal people of mixed descent was to 'fuck 'em up white' ${ }^{7}$ In dealing with the legacy of this era, however, in striving to negate the sense of having an identity deemed unsavoury or incomplete, are some of the repugnant ideologies underpinning the notion of absorption remanifesting? Whether consciously or otherwise, has the intended eugenicist project simply been reversed through the taking of non-Aborigines as consorts to 'fuck 'em up black?'

If the notion of absorption of black into white is the subject of scrutiny, as it should be, so too should be the adopted practice of extirpating non-Indigenous heritage. From the 2001 census we know that 69 per cent of couples with an Aboriginal partner are intermixed. ${ }^{8}$ In capital cities this rises to 87 per cent. ${ }^{9}$ The aforementioned 1937 conference would have expected such a high rate of intermarriage to be responsible for a marked and escalating reduction in the number of Aboriginal people, but the contrary is happening. Rather than identifying as white, or non-Indigenous, or something other than Aboriginal that embraces mixed descent, the descendants of mixed marriages between black and white tend to identify as Aborigines. According to Bob Birrell and John Hirst, this 'is an important source of the rapid growth in the self-identified Aboriginal population in Australia'. ${ }^{10}$ The Centre for Aboriginal Economic Policy Research Unit goes further, suggesting that this could well be the only source of growth. This is because indigenous women's fertility is now at or below replacement level. Besides any

\footnotetext{
Anderson 1997: 12.

Commonwealth of Australia 1937 (unpaginated).

Manne 2001: 17.

. The increase in intermixed Aboriginal-settler Australian couples can be gauged from the following census data: 198646 per cent; 199151 per cent; 199664 per cent (Birrell 2000: 62-3).

9. Birrell and Hirst 2002

10. Birrell and Hirst 2002; see also Birrell 2000: 62, 63-5.
} 
increase in identification and the growth already contained within the relatively young age structure, 'only the contribution made by Indigenous births to non-Indigenous women ... will now sustain Indigenous population growth' ${ }^{11}$ Whilst we can presume that today most if not all intermixed child-producing unions are entered into voluntarily, or at least without state coercion, the identity imposed upon or assumed by the children and their descendants is not so innocent. There are various investments in and sensitivities surrounding this issue, not the least being the perceived threat or otherwise to the integrity of Aboriginal cultural survival. Greg Gardiner and Eleanor Bourke allude to these exigencies in an article critical of how the Australian Bureau of Statistics explain Indigenous population growth, particularly in relation to identity. Gardiner and Bourke posit that - rather than intermarriage being a threat to Indigenous peoples because of reported fears of cultural dilution - settler Australian identity 'could well be ... standing in line for "dilution"' ${ }^{12}$ Manifestly a vast legislative and policy complex, and an array of political, historical, educative, communal, cultural, social and psychological exigencies function to coerce particular identities, even ones apparently voluntarily assumed. For example, the only way that an Aboriginal heritage is formally and popularly recognised is through the assumption of Aboriginality. Despite these pressures, children do not always assume the racial, ethnic and/or cultural identity expected of them by others, including parents and/or communities. Children can identify at variance to their ostensible phenotype, and siblings can assume (or are allocated or otherwise have imposed upon them) different identities. ${ }^{13}$ Nevertheless, pressures to adopt particular identities remain. A young student who wished to acknowledge both sides of her biological and cultural heritage and who was desirous of an inclusive identity, uncertain as to what to say when challenged in the politically-charged environment of the university Aboriginal Studies centre in which I work, mumbled she 'was descended from Aborigines.' An Aboriginal staff member - herself a person of mixed descent - pounced with the reprimand 'I hate it when people say that'. ${ }^{14}$

Direct comparisons with North America on the issue of the identity of people of mixed descent is difficult. One might surmise that any such comparison should be with Native Americans. However, Native Americans have not faced the same legal (and social) barriers to miscegenation as African Americans, and the exogamy rate has always been comparatively high. The 1990 census revealed that 59 per cent of Native American marriages were intermixed ${ }^{15}$ and a national survey conducted in 1993 reported a rate of 70 per cent. ${ }^{16}$ These figures need qualifying. Rachel Moran argues that '[e]arly intermixing of white and Native American populations has blurred personal racial identifications, so that people readily shift their identities in response to

11. Kinfu and Taylor 2002: iv.

12. Gardiner and Bourke 2000: 46. Whilst not speaking of miscegenation nor of the identity assumed by those of mixed descent, but rather of the cultural, social and philosophical influence of Aboriginal history and the Aboriginal presence on settler Australians, the Australian poet Les Murray has mused on the figurative inevitability of becoming an Aborigine: ‘Gradually you become them. Every invader, every settler gradually becomes the people who are conquered' (Murray 1992: 32).

13. Root 2001: 152.

14. 15 August 2001.

15. Moran 2001: 108.

16. Brown and Douglass 1996: 325. 
changing policy'. ${ }^{17}$ Furthermore, children born of Native American-white couples where there are high rates of intermarriage (such as in areas where the Native American population is dispersed and/or urbanised) are often classified as white by the parents. Those with remote Native American ancestry 'treat their Indian identity as optional' ${ }^{18}$ This is not the case in Australia. Irrespective of population characteristics, intermixed Aboriginal-settler Australian couples are likely to categorise their children as Aboriginal, and raise their children in the expectation that they will assume an Aboriginal identity. Such racialisation is much more a feature of how African Americanwhite couples rather than Native American-white couples categorise their children. ${ }^{19}$ Reginald Daniel notes how 'African ancestry ... is passed on in perpetuity as a means of socially designating all future offspring as black, and thus it precludes any notion of choice in self-identification' ${ }^{20}$ Such racialised essentialism has attracted broad support. Indeed, until very recently a wide cross-section of professionals in North America argued that the sound mental health of children of mixed black-white descent was dependent upon them successfully assuming an African American identity. ${ }^{21}$ It should be noted that the research upon which this argument is based is characterised by its paucity, not depth, is frequently contradictory, and/or is specific research from which generalist application should not have been extrapolated. Nevertheless, despite the number of African American-white intermixed marriages nearly doubling from 1981 to 1991 (121,000 to 213,000 couples), and increasing again in 1998 to 330,000 couples, compared to Aboriginal people the rate of miscegenation is very low. Of the total number of marriages in North America in 1998, 0.6 per cent comprised African American-white marriages. Out of all marriages involving an African American spouse in 1990 only six per cent were interracial marriages. ${ }^{22}$ Thus in terms of identity politics, whilst there are close parallels between children of African American-white descent, and Aboriginalsettler Australian descent, there is a wide disparity in rates of miscegenation.

Another feature distinguishing between how Native Americans and Aboriginal people identify is their response to 'blood quantums'. Whereas many Aboriginal people (and Australian government agencies and service providers) subscribe to the 'one drop' rule as being sufficient biological quantum for an individual to assume an Aboriginal identity - subject to also satisfying other criteria ${ }^{23}$ - in order to be classified Native

\footnotetext{
Moran 2001: 108.

Moran 2001: 109.

Moran 2001: 105.

Daniel 1996: 130, his emphasis.

21. Daniel 1996: 127. A similar notion appears to have currency in Australia in respect to mixed descent children assuming an Aboriginal identity. Aboriginal Child Placement Principles, adopted through policy and/or legislation in one form or another in every Australian State and Territory, have as their basis this assumption. See Human Rights and Equal Opportunity Commission 1997: 439-79, 581-90; Law Reform Commission 1997.

22. See Root 2001: 179-88; Kennedy 2003: 126-7.

23. There is no unitary definition of who is an Aborigine or Torres Strait Islander. Nevertheless, access to many targeted federal and State services and programs depends upon Aborigines or Torres Strait Islanders satisfying a threshold test. This test stipulates that an Aboriginal or Torres Strait Islander is someone who: 1) is of Australian Aboriginal or Torres Strait Islander descent; and 2) identifies as an Australian Aboriginal or Torres Strait Islander; and 3) is accepted as such by the community in which s/he lives or has lived. See Gardiner-Garden 2003: 1 .
} 
American by the Bureau of Indian Affairs individuals must be of at least one-fourth Native American 'blood quantum.' In addition some tribes set their own membership criteria and various 'blood quantums' are used as entry benchmarks. ${ }^{24}$ Nevertheless, apropos to Gardiner's and Bourke's comment about settler Australian identity 'standing in line for "dilution," 25 the US Bureau of the Census predicts that by 2050 'the representative face of America will no longer be white' ${ }^{26}$

Notwithstanding the Indigenous desire to reclaim a sense of authenticity formerly denied, there is an obvious political efficacy in Aboriginal communal coercion and individual advocacy (both grass root and elite) to sway people of mixed descent to forego their non-Indigenous heritage and proclaim loudly their Aboriginality. Aboriginality, not recognition of mixed heritage, determines access to targeted services, and is a requisite underlying the ability to make successful land rights and native title claims, amongst other things. Acknowledgement and acceptance of Aboriginality, particularly in southern Australia including Tasmania, has been vital. A consequence however is that political (and other) expediencies have a way of hardening cultural and social arteries, thereby restricting innovative flow and stifling dynamism, change and growth. Furthermore, the ostensible oppositional radicalism of denying non-Indigenous heritage in assertions of Aboriginality all too often segues into a racialisation that allows little more than a recitation of traditional contrivances, ${ }^{27}$ or emotive appeals to a heartfelt true inner black self. ${ }^{28}$ The orthodox understanding that culture is learned also comes under challenge. Culture, like phenotype, is treated as if it too is innate. Under the one-drop rule Indigenous (and/or black) descent is held to imbue one with, or allow one access to, a range of inherent values and qualities. ${ }^{29}$ Pertinent to this paper, however, is the question of why in Australia there is so little analytical interest in the elision of all but a singular cultural and biological heritage? ${ }^{30}$

The rhetorical and semantic context in which this extirpation takes place is also of consequence. The manner of the British acquisition of Australia is under dispute. Was it by discovery, occupation, conquest and/or cession? ${ }^{31}$ Whatever, the complex, enduring and tangled processes of colonisation are now glibly glossed as invasion, and the colonisers as invaders. Martial diction and a plethora of descriptors of and metaphors for

\footnotetext{
Ramirez 1996: 56.

Gardiner and Bourke 2000: 46.

Cited in Root 1996a: xiv.

See Memmi 1965: 98-100.

8. See Hall 1990: 226-7, and passim.

29. For discussion on how this understanding affects judicial decisions in the United States in transracial adoptions, see Kennedy 2003: 444-5, 467-8, and passim. See also Lowenthal 1998: 222.

30. There's anecdotal evidence that in Broome people of mixed heritage are more inclined to acknowledge and celebrate all their ancestral lines, or at least those other than any white forebears. One can speculate that this is in part motivated by the appeal of the exotic. A Japanese pearler, Afghan cameleer, Chinese cook, gardener or laundryman, Filipina deckhand and so on, all take one into new and exotic locales, cultures, peoples, and away from the supposed blandness and badness of the white 'invaders.' Again, anecdotally, a growing number of young Aborigines are expressing a desire to embrace and name their complex heritage.

31. Reynolds 1996: 86-107.
} 
war describe both past and present encounters and relations between black and white. Certainly many Aboriginal people argue that Australia was invaded, invasion continues and that ipso facto, an ongoing war is being fought. Before a 1983 Senate Committee central Australian Aborigines argued that 'Aboriginal people have never surrendered to the European invasion and assert that sovereignty over all of Australia lies with them' ${ }^{32}$ Not only is the alleged war over territory. 'It's a cultural war' Professor Marcia Langton declared in a millennial conference address. ${ }^{33}$

If we accept that there is an unfinished and ongoing war - and ostensibly we do, for credible critiques of this view of affairs are few - what then of sexual relations between black and white that result in offspring whose duty is to proclaim one identity, heritage and cultural influence at the expense of the other? Certainly in North America some saw the demanded elision of white heritage as part of their soldierly duty. Speaking of her 'mixedness' and the recent movement towards recognition of 'multiracial' identities, the journalist and novelist Danzy Senna recalls she and her siblings being pressed into service by their black father as 'his soldiers in the battle for negritude' ${ }^{34}$ In the introduction of her Miscegenation blues: voices of mixed race women, the editor Carol Camper, who whilst of mixed descent identifies as black, writes that ' $[\mathrm{t}]$ he invasion of women's bodies is always a device of war' ${ }^{35}$ Under this dated and gloomy assessment of sexual intimacy, intermixed children born of white women are racial and cultural myrmidons. More prosaically a former Aboriginal colleague once worked for a large, well-funded, well-staffed State-based Aboriginal office that oversees and administers a raft of programs and projects. Its staff, affiliates and supporters believe they are the only local Aborigines, and as a corollary, believe they should have the authority to sanction and disavow the claims of others to Aboriginality. My colleague confided his unease at the unceasing office refrain of 'fucking whites', an epithet always hurled in anger. Somewhat ironically, it was also taken literally. Everyone in the office, without exception, was of mixed descent, and all, again without exception, had non-Indigenous, white partners. ${ }^{36}$

There is much literature considering the issue of rape in war, and how forced impregnation is not only an instrument of terror but - through purposefully hindering the reproductive continuation of a people by distorting their ethnic composition - an instrument of ethnocide. This occurrence has been given legal definition by the Rome Statute of the International Criminal Court. ${ }^{37}$ The vexed and complex issue of the rights and identity of any resulting children is one also taken up in this literature. ${ }^{38}$ Whilst there is a great deal of literature (and policy and legislation past and present) dealing with bi- and multiracial children, there is little material (analytical or otherwise) discussing the issue of consensual sexual relationships betwixt opposing parties in a war zone and the ramifications of this in terms of the identity of any resulting offspring. The significance of this is that, as in Australia there is a supposed ongoing territorial and

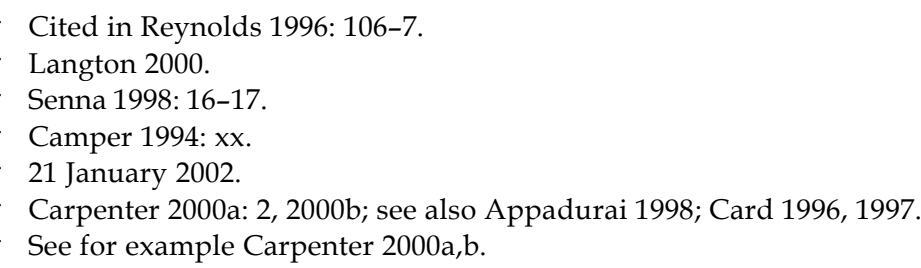


cultural war, amongst other things Australia itself is a war zone. Consequentially, if this is war then consensually procreating intermixed couples can hardly be described as naive. Whether they are conscious of the fact or not, and presumably many are not, they are in fact part of the armoury, an offensive weapon wielded against whitey. ${ }^{39}$ Although now coming under challenge by those seeking to embrace a bi- or multiracial identity, sentiments similar to this sustain African American interest in retaining the 'one drop' rule in respect to identity. Whilst the rule of hypodescent ${ }^{40}$ was first implemented in an explicit attempt to preserve white privilege and white racial and cultural purity, many African Americans now view the one-drop rule 'as a necessary, if originally oppressive, means not only of maintaining a distinct but equal African American racial and cultural plurality, but more important, of mobilising blacks in the continuing struggle against white privilege' ${ }^{41}$ Further witness to this is the opprobrium apportioned to prominent individuals of black descent who publicly express a bi- or multiracial identity. When Tiger Woods rejected the categories Black and African American and proclaimed himself to be Cablinasian (from Caucasian, Black, Indian and Asian) he was accused of shirking his real identity - that of an African American. ${ }^{42}$ The charge is laid that the assumption of a blended identity strategically evades 'the societal stigma attached to blackness' ${ }^{43}$

And what of consent itself in respect of intermixed procreating couples? A moral unease has haunted many colonisers and settler Australians from the commencement of European occupation. Even the instruction to live 'in amity and kindness' with Aborigines issued to Governor Phillip contains a tacit moral concern over the presence of Aboriginal people. Those who gave voice to their concerns include both sensitive and hardy pragmatic folk; the uneducated and the highly educated. ${ }^{44}$ Even the most passionate and articulate defenders of Aboriginal dispossession confessed disquiet. 'What means this whispering in the bottom of our hearts,' introspected Richard Windeyer, an otherwise forthright barrister whom Reynolds describes as 'one of the ablest apologists for European colonisation' ${ }^{45}$ The matter of the legitimacy of non-Indigenous occupation of Australia, Aboriginal dispossession and the manner in which these occurrences were achieved are issues of public concern and dispute. Bearing witness to this is the broad interest in and ongoing public debate over the issues raised by Keith Windschut-

39. I'm not drawing a comparison in this paper between inter-racial sexual relations on the frontier which occurred 'largely within a context of unfreedom, exploitation and terror' (Evans 1982: 9 and following) and the imposition of a singular identity upon children now born of mixed marriages. This paper is concerned with specific aspects of the latter.

40. The formal term for the 'one-drop of blood' rule, whereby a person with any trace at all of African ancestry is deemed to be black.

41. Daniel 1996: 132, 122-3.

42. Kennedy 2003: 143-4; Moran 2001: 159. See Root (1996a: ix-xi) and Daniel (1996: 127) for a glossary of terms used to describe people of mixed descent. See Senna (1998: 23-7) for a caustic glossary derived from 'Variations on a theme of a Mulatto'. Senna treats any embracing of hybrid identities - such as Woods' self-identification as Cablinasian - with derision (see Senna 1998: 12-27). An editorialist was similarly dismissive, describing Woods' motives as deriving from 'an almost Star Trekian brand of humanism', before chiding him (unfairly) for self-interestedly side-stepping 'the race debate' (cited in Moran 2001: 159).

43. Daniel 1996: 129; see also Lowenthal 1998: 210; Reddy 1994: 68.

44. See Reynolds 1987.

45. Reynolds 1987: 162. 
tle's recent publication. Windschuttle alleges that the accepted version of Aboriginalnon-Aboriginal history in Tasmania attesting to widespread and deliberate killings of Aboriginal people and a state of war between black and white, is a fabrication unsupported by evidence. $^{46}$

Many claims are made as to the effect that colonisation and its legacy has had on the psyche of settler Australians. Bernard Smith argued in the 1980 Boyer lecture series that Australians are beset by unresolved guilt. ${ }^{47}$ That settler Australians are alienated from ourselves, the landscape we inhabit and suffer a spiritual void are common assertions: so common in fact that many accept such assertions as a given, and it is a mindset that has permeated both popular and esoteric culture. As Andrew Lattas discusses, '[s]elf-alienation is a theme that haunts Australians. It is made to haunt them. It is something they haunt themselves with ... Situated in an alien landscape, white settler Australians are made to internalise a sense of not being at home with themselves' ${ }^{48}$ Nor at home in the land we inhabit. So acutely has the historian of Aboriginal Tasmanians Lyndall Ryan ${ }^{49}$ internalised this constructed notion of illegitimacy and alienation she desires to have her ashes scattered at sea, for in her words, 'it is neutral territory over which no human may lay claim. And therefore I have the right to have a relationship with it because I'm not treading on anyone's toes. ${ }^{50}$ Judith Wright, one of Australia's foremost poets and environmentalists, also expressed ambivalence towards Australia: 'Those two strands - the love of the land we have invaded, and the guilt of the invasion - have become part of me. It is a haunted country. ${ }^{51}$ The historian Bain Attwood alludes to this discomfiture too in his book Rights for Aborigines. Attwood suggests that in order to understand the motivation of non-Aboriginal activists for Aboriginal rights throughout all of post-contact history, psychological factors must be considered. He concludes, furthermore, that unless " rights for Aborigines" in all their forms' are recognised, the moral legitimacy of the Australian nation will be forever denied, and none of us will ever 'be truly at home in this world' ${ }^{52}$ Germaine Greer argues in her recent essay that guilt pervades the settler Australian conscience. ${ }^{53}$ Following the release of the report of the National Inquiry into the Separation of Aboriginal and Torres Strait Islander Children from Their Families ${ }^{54}$ and the subsequent publicity, a sense of disquiet for some has escalated into something resembling self-hatred. The Sorry Books ${ }^{55}$ are littered with comments such as 'I often feel ashamed to be white.' Says another, 'I am deeply ashamed of my skin colour as a white Australian.' And another, 'I'm disgusted at what my ancestors have done ... I do not feel that I am a part of this arogant (sic) ignorant dominate (sic) culture.' Someone else,

46. Windschuttle 2002. For responses to Windschuttle's thesis see Manne 2003 and Macintyre and Clark 2003.

47. Smith 1980.

48. Lattas 1990: 54-5.

49. See Ryan 1996 [1981].

50. Cited in Read 2000: 197

51. Wright 1991: 30.

52. Attwood 2003: xiii, 349 and following.

53. Greer 2003

54. Human Rights and Equal Opportunity Commission 1997. 
'I am sometimes ashamed to be white', and on and on such exculpatory narcissism goes.

Aboriginal people are pivotal to these themes of unease, guilt, alienation, illegitimacy, self-hatred and angst. ${ }^{56}$ Whilst many Aborigines are ever ready to exploit the unease felt by settler Australians and indeed extract political efficacy from it, more often settler Australians haunt themselves with this unease. However, irrespective of intention and where agency lies, the Aboriginal presence in Australia appears to be responsible for spawning a range of mild psychopathologies. In other words, it could be argued that settler Australian responses to the Aboriginal presence are functioning to imprison us within certain psychological and behavioural forms, such as the various manifestations of self-beratement and guilt. ${ }^{57}$ Given this, could it be that Aborigines being a set of disruptive and unsettling elements generating a particular set of responses (guilt, alienation, illegitimacy, and so on) - unconsciously are functioning as the psychological captors of settler Australians. If so, then settler Australians, as captives of long duration, might be expected to begin over-identifying with their psychological captors, thus experiencing a subtle manifestation of Stockholm syndrome.

There is no universally agreed aetiology of Stockholm syndrome, ${ }^{58}$ nor even agreement as to what it actually is. The name dates from an incident in Stockholm in August 1973 when an armed robber held four bank employees hostage for six days. Despite periodic threats to harm the hostages, even to kill them unless certain demands were met, some began to identify with their captor and criticise those attempting to rescue them. Their response was rationalised as a defence mechanism - employed either consciously or unconsciously - through which captives seek to ameliorate their stress and avoid harm.

With the naming and describing of Stockholm syndrome came the ability to test its relevance across varied and wider fields. As an indication of the sort of hypotheses advanced, some find in the syndrome an explanation for the relationship between battered wives and their abusers. Dee Graham, associate professor of psychology, University of Cincinnati, uses the term 'societal Stockholm syndrome' in her suggestion that all women are held in a state of captivity and fear by a (potentially) universally vio-

55. The Report of the National Inquiry into the Separation of Aboriginal and Torres Strait Islander Children from Their Families recommended the holding of an annual 'Sorry Day' for the purposes of commemorating 'the history of forcible removals and its effects' (Human Rights and Equal Opportunity Commission 1997: 652 s7a). The organization Australians for Native Title proposed the addition of 'Sorry Books' that would allow settler Australians to express their regret and personal apologies over the forced removal of indigenous children. These books have become an integral part of Sorry Day activities throughout Australia. The comments cited are from one of the books made available for further expressions of regret each 'Sorry Day' at the University of Tasmania. Reading through many other 'Sorry Books' demonstrates that the comments are not atypical.

56. It's important here to understand that I am not according settler Australians the status of victim, nor Aboriginal people the status of aggressors. Rather, I am seeking to further understand the responses of settler Australians to their increased awareness, comprehension and acknowledgment of black-white relations in Australia, historically and currently.

57. Gooder and Jacobs 2000: 229-47.

58. See Graham 1994: 24-9. 
lent patriarchy. Graham argues that through extrapolating Stockholm syndrome from the specific (an incident) to the general (society), male-female relations and women's psychology can be best understood. ${ }^{59}$

I'm not implying agreement nor disagreement with Graham's thesis vis-a-vis male-female relations here. It is her application of Stockholm syndrome to the broader sociocultural sphere that is of significance, as is her recognition that violence - a necessary catalyst in the development of the syndrome - need only be psychological. The relevance is that whilst there is no doubt that Aboriginal people in general are more the subjects of white violence and oppression than whites are of Aboriginal violence, it is also manifestly apparent in the aforementioned discussion that unresolved issues between black and white within Australia are troubling the settler Australian conscience. This unresolved conflict, in part ideological and in part political, is of an enduring nature, and over the last two or three decades an increasing number of Australians have come to understand Aboriginal grievances, to feel they are legitimate, and on some level to identify with them. As noted, a consequence of this is a questioning of one's sense of self, belonging, and legitimacy. If these forms of identification are arising from the expressed feelings of guilt, alienation, and so forth, and if Stockholm syndrome does have cadence beyond the specific to the extent that it resonates at a sociocultural level, then perhaps it does offer insight into black-white relations in Australia. Following the line of this explanation, could this offer one reason why so many non-Indigenous partners within intermixed procreating relationships appear comfortable having their offspring elide one heritage and identity - their non-Indigenous heritage - for the sake of another - that of Aboriginal heritage? Could this be one reason why in Australia there is so little analysis of this elision? Could this be one explanation (amongst many) for the high rate of intermixed procreating couples?

There are many ways of being Australian, and Aboriginality, like any other identity, is open to myriad possibilities. But an Aboriginality that forecloses against recognition of mixed descent and the genetic and cultural influences of all forebears is in some instances disingenuous. Furthermore, to allow a person of mixed descent to exist in their own complex right, as we are asked to do, requires recognition and acceptance of all lines of descent. The policy of assimilation sought to 'breed out the black strain' and, through cultural coercion, to eliminate Aboriginal cultural and biological heritage. It could be argued that the elision of white heritage in current identity politics - on an individual level at least - is hand-in-hand with the same (repugnant) ideology. Here too, particularly in the ideological shadows of the unguarded comment, one witnesses the unfolding of yet another eugenicist project. One that is, however, now under challenge. Randall Kennedy notes how in the United States many thousands of people of mixed ancestry 'have begun to insist upon public recognition of the full complexity of their lives', ${ }^{60}$ and are eschewing monoracial and/or monocultural identities. So successful have these demands been that the US Bureau of the Census now allows individuals to indicate multiracialism on the census. ${ }^{61}$ Even this is not

59. Graham 1994.

60. Kennedy 2003: 144.

61. Moran 2001: 154-78. Moran provides an interesting analysis of the significance of this change, including a critique of how the data will be re-aggregated, and some of the consequences. 
going far enough for some. Says one biracial woman, 'People are already talking about giving us a heritage, ... making us a census box. I want to see the day when there are no boxes' ${ }^{62}$ Professor Maria Root, of Filipino, Spanish, Chinese, Portuguese, German and Irish heritage, has written 'A Bill of Rights for Racially Mixed People'. ${ }^{63}$ Included amongst the twelve rights is the right 'not to keep the races separate within me.' Root explains that she does not 'want to fit into a system that does not accommodate [her] reality'. ${ }^{64}$ For various reasons, some will always assert and privilege a unitary identity and heritage, and (as discussed) acceptance of this is and has been crucial for many in the restoration of dignity, respect, and the realisation of certain rights. But Reynolds' call for the recognition of a Creole identity, or some such, is overdue, and its pertinence is not confined to Tasmania, but is Australia-wide. Both black and white need to confront this.

\section{References}

Anderson, I 1997, 'I, the "hybrid" Aborigine: film and representation', Australian Aboriginal Studies (1): 4-14.

Appadurai, A 1998, 'Dead certainty: ethnic violence in the era of globalisation', Public Culture 10(2): 225-47.

Ashcroft, B, Griffiths, G and Tiffin, H 1995, 'Introduction', in B Ashcroft, G Griffiths and H Tiffin (eds) The post-colonial studies reader, Routledge, London: 183-4.

Attwood, B 2003, Rights for Aborigines, Allen and Unwin, Crows Nest.

Birrell, B 2000, 'Intermix and Australia's indigenous population', People and Place 8(1): 61-6.

Birrell, B and Hirst, J 2002, 'Aborigines: the real story', The Age, 15 August: 15.

Brown, NG and Douglass, RE 1996, 'Making the invisible visible: the growth of community network organisations', in MPP Root (ed) The multiracial experience: racial borders as the new frontier, Sage Publications, Thousand Oaks: 323-40.

Camper, C 1994, 'Into the mix', in C Camper (ed) Miscegenation blues: voices of mixed race women, Sister Vision Press, Toronto: xv-xxiv.

Card, C 1996, 'Rape as a weapon of war', Hypatia 11(4): 5-19.

- 1997, Addendum to 'Rape as a Weapon of War', Hypatia 12 (2): 216-19.

Carpenter, RC 2000a, 'Assessing and addressing the needs of children born of forced maternity', Submission to the Secretariat of the International Conference on WarAffected Children, Winnipeg, Canada, 11-17 September 2000, http:/ / www.waraffectedchildren.gc.ca/orphans-e.asp (accessed 22 September 2005): 1-4.

-2000b, 'Surfacing children: limitations of genocidal rape discourse', Human Rights Quarterly 22: 428-77.

Commonwealth of Australia 1937, 'Aboriginal welfare', Initial Conference of Commonwealth and State Aboriginal Authorities, Commonwealth of Australia, Canberra.

62. Cited in Lowenthal 1998: 218.

63. Root 1996b: 3-14.

64. Root 1996b: 7, 8. See also Daniel 1996: 127. 
Daniel, G Reginald 1996, 'Black and white identity in the new millennium: unsevering the ties that bind', in MPP Root (ed) The multiracial experience: racial borders as the new frontier, Sage Publications, Thousand Oaks: 121-39.

Evans, R 1982, “"Don't you remember Black Alice, Sam Holt”? Aboriginal women in Queensland history', Hecate viii(2): 6-21.

Gardiner, G and Bourke, EA 2000, 'Indigenous populations, "mixed" discourses and identities', People and Place 8(2): 43-52.

Gardiner-Garden, J 2003, 'Defining Aboriginality in Australia', Current Issues Brief, 10: 1-32.

Gooder, H and Jacobs, JM 2000, “'On the border of the unsayable”: the apology in postcolonising Australia', Interventions 2(2): 229-47.

Graham, DLR 1994, Loving to survive: sexual terror, men's violence, and women's lives, New York University Press, New York.

Greer, G 2003, 'Whitefella jump up: the shortest way to nationhood', The Australian Quarterly Essay (11): 1-78.

Hall, S 1990, 'Cultural identity and diaspora', in J Rutherford (ed) Identity: community, culture, difference, Lawrence \& Wishard, London: 222-37.

Human Rights and Equal Opportunity Commission 1997, Bringing them home: national inquiry into the separation of Aboriginal and Torres Strait Islander children from their families, Human Rights and Equal Opportunity Commission, Canberra.

Kennedy, R 2003, Interracial intimacies: sex, marriage, identity, and adoption, Pantheon Books, New York.

Kidd, R 1997, The way we civilise: Aboriginal affairs - the untold story, University of Queensland Press, St Lucia.

Kinfu, Y and Taylor, J 2002, Estimating the components of Indigenous population change, 1996-2001, CAEPR Discussion Paper no 240/2002, Centre for Aboriginal Economic Policy Research, Australian National University, Canberra.

Langton, M 2000, 'The “ $R$ " word reconciliation': address to the National Diversity Conference, University of Technology, Sydney, Awaye, Producer N Guivarra (ABC Radio National, 8 December 2000).

Lattas, A 1990, 'Aborigines and contemporary Australian nationalism: primordiality and the cultural politics of otherness', Social Analysis (27): 50-69.

Law Reform Commission 1997, Legislation, policy and practice across Australia, 'Research Report 7 (1997) - The Aboriginal child placement principle', New South Wales Attorney General's Department, Sydney, http:/ / www.lawlink.nsw.gov.au/ 1rc.nsf/pages/RR7CHP5 (accessed 22 September 2005).

Lowenthal, D 1998, The heritage crusade and the spoils of history, Cambridge University Press, Cambridge.

Macintyre, S and Clark, A 2003, The history wars, Melbourne University Press, Carlton South.

Manne, R 2001, 'In denial: the stolen generations and the right', The Australian Quarterly Essay (1): 1-113.

Manne, R (ed) 2003, Whitewash: on the fabrication of Aboriginal history, Black Inc, Australia. 
Memmi, A 1965 [1957], The coloniser and the colonised, Beacon Press, Boston.

Moran, R 2001, Interracial intimacy: the regulation of race and romance, University of Chicago Press, Chicago.

Murray, L 1992, 'Embracing the vernacular, interview by N Peacock', Australia and New Zealand Studies in Canada (7): 28-40.

Pos, M 2002, ‘When cultures clash: Aboriginality. It's not a question of black or white, a respected historian tells Margaretta Pos', The Saturday Mercury, 14 September: 37-8.

Ramirez, DA 1996, 'Multiracial identity in a color-conscious world', in MPP Root (ed) The multiracial experience: racial borders as the new frontier, Sage Publications, Thousand Oaks: 49-62.

Read, P 2000, Belonging: Australians, place and Aboriginal ownership, Cambridge University Press, Oakleigh.

Reddy, MT 1994, Crossing the color line: race, parenting and culture, Rutgers University Press, New Brunswick.

Reynolds, H 1987, Frontier: Aborigines, settlers and land, Allen \& Unwin, St Leonards.

_ 1996, Aboriginal sovereignty: three nations, one Australia, Allen \& Unwin, St Leonards.

Root, MPP 1996a, 'The multiracial experience: racial borders as a significant frontier in race relations', in MPP Root (ed) The multiracial experience: racial borders as the new frontier, Sage Publications, Thousand Oaks: xiii-xxviii.

— 1996b, 'A bill of rights for racially mixed people', in MPP Root (ed) The multiracial experience: racial borders as the new frontier, Sage Publications, Thousand Oaks: 3-14.

- 2001, Love's revolution: interracial marriage, Temple University Press, Philadelphia.

Ryan, L 1996 [1981], The Aboriginal Tasmanians, Allen \& Unwin, St Leonards.

Senna, D 1998, 'The mulatto millennium', in CC O'Hearn (ed) Half and half: writers on growing up biracial and bicultural, Pantheon Books, New York: 12-27.

Smith, B 1980, The spectre of Truganini, Australian Broadcasting Commission, Sydney.

Windschuttle, K 2002, The fabrication of Aboriginal history: volume one: Van Diemen's Land 1803-1847, Macleay Press, Paddington.

Wright, J 1991, Born of the conquerors, Aboriginal Studies Press, Canberra. 